\title{
ANALISA MATEMATIS PADA KOREKSI BOUGUER DAN KOREKSI MEDAN DATA GRAVITASI SATELIT TOPEX DALAM PENENTUAN KONDISI GEOLOGI STUDI KASUS SESAR PALU KORO, SULAWESI TENGAH
}

\author{
Aji Darma Maulana ${ }^{1}$, Danang Aji Prasetyo ${ }^{2}$ \\ ${ }^{1}$ Teknik Geofisika, Fakultas Teknologi Mineral, Universitas Pembangunan Nasional “Veteran” Yogyakarta, Indonesia \\ ${ }^{2}$ Teknik Geologi, Fakultas Teknologi Mineral, Universitas Pembangunan Nasional "Veteran” Yogyakarta, Indonesia \\ e-mail : ajiedarma16@gmail.com
}

\begin{abstract}
Abstrak. Tahapan pengolahan geofisika merupakan tahapan krusial pada suatu penelitian. Ketepatan serta pemahan sifat koreksi nilai gravitasi sangat diperlukan agar hasil pengukuran geofisika mencerminkan keadaan bumi sebagaimana mestinya. Penelitian ini menggunakan data gravitasi hasil observasi Satelit TOPEX dengan luas area pengukuran $37.530 \mathrm{~km}^{2}$ dan data yang didapat berupa Free Air Anomaly. Penelitian ini menerapkan analisa matematis pada koreksi bouguer dan koreksi medan untuk menghasilkan representasi data yang memiliki kesesuaian antara data geofisika dengan kondisi geologi sebenarnya. Analisa dilakukan dengan cara membandingkan empat variasi pengolahan koreksi bouguer dan koreksi medan pada nilai Free Air Anomaly. Pengolahan tersebut dilakukan dengan cara memperkecil perbedaan nilai koreksi bouguer dan/atau koreksi medan yang terlalu besar sebagai akibat dari perbedaan elevasi yang terlalu signifikan. Dari keempat pengolahan tersebut menghasilkan empat peta anomali bouguer lengkap dengan pola ekspresi yang berbeda. Didapatkan anomali bouguer lengkap yang merepresentasikan keadaan geologi sebenarnya pada peta yang telah diperkecil perbedaan nilai pada koreksi bouguer dan koreksi medan. Terlihat kemenerusan anomali gravitasi dengan orientasi relatif Utara-Selatan yang diinterpretasikan sebagai sesar mendatar. Serta beberapa kemenerusan dengan orientasi relatif barat lauttenggara yang diinterpretasikan sebagai sesar penyerta. Anomali tersebut berada pada kisaran nilai $7.1-$ $39 \mathrm{mGal}$ pada peta anomali bouguer lengkap serta pada area sudut rendah peta tilt derivative dengan nilai $-1.5-0.5$ derajat. Keberadaan dan persebaran densitas yang mencerminkan litologi maupun sesar daerah penelitian telah tervalidasi oleh peta geologi dan ekpresi topografi data SRTM berdasarkan analisa anomali gravitasi.
\end{abstract}

Kata kunci: analisa matematis; sesar mendatar; koreksi bouguer; koreksi medan; gravity satelit.

\begin{abstract}
Correction and reduction have to be done to the satellite gravity observation data in order to obtain the Complete Bouguer Anomaly Map that represents the actual geological circumstance. This study is carried out using the TOPEX Satellite gravity observation data, in the form of Free Air Anomaly data, comprising $37.530 \mathrm{~km}^{2}$ area. Mathematical analysis of Bouguer correction and Terrain correction are applied to produce a representative map that reflects the actual geological circumstance. We compared four data treatment variations related to the Bouguer correction and Terrain correction. We attempted to reduce the Bouguer and/or Terrain correction that has extreme contrast difference value as a result of a significant difference between the maximum and minimum elevation. These four variations of data treatment yielded four different maps and each of them shows a distinctive pattern. A representative Complete Bouguer Anomaly Map that shows the actual geological circumstance is obtained by reducing the significant value contrast of both Bouguer and Terrain correction. A North-South lineament of gravity anomaly is apparent on the map and estimated as the Palu-Koro Fault. Several numbers of NortheastSouthwest lineaments can also be distinguished and interpreted as a fault as well. Those anomalies range from 7,1 - $39 \mathrm{mGal}$ in Complete Bouguer Anomaly Map. In the tilt derivative map, we can also trace the lineament reflected by the low tilt angle ranging from $-1.5-0.5$ degrees. The gravity data analysis also shows some areas with low density. Those areas are suspected as sedimentary rock areas in which liquefaction risk is higher. The result of this study has been proven coherent with the geologic map created by the preceding researchers and the result of SRTM data analysis.
\end{abstract}

Keywords: mathematical analysis; strike-slip fault; bouguer correction; terrain correction; satellite gravity.

\section{PENDAHULUAN}

Indonesia merupakan negara yang berada di batas-batas lempeng paling aktif di dunia. Hal tersebut membuat Indonesia sangat rentan terhadap bencana gunung api, gempa bumi dan bencana-bencana lain yang berhubungan dengan

Artikel diterima 15 November 2019, Revisi 1 Desember 2019 Online 15 Desember 2019.

http://dx.doi.org/10.12962/j25023659.v5i3.6100 
kegempaan seperti tsunami dan likuifaksi. Salah satu bencana tsunami terbesar yang melanda Indonesia adalah tsunami yang diakibatkan letusan Gunung Krakatau pada tahun 1883 (Harris \& Major dalam Cummins, 2017). Symons menyatakan bahwa pada 27 Agustus terjadi empat letusan besar yang merupakan puncak dari aktivitas Gunung Krakatau pada masa itu. Letusan terjadi pada 05:30, 06:44, 10:02, dan 10:52, dengan letusan terbesar terjadi pada pukuL 10:02 (Symons dalam Nomanbhoy dan Satake, 1995). Letusan tersebut terdengar hingga sekitar 4000 km menyebrangi Samudra Hindia. Abu vulkanik tersebar ke berbagai daerah dan suhu di berbagai tempat di belahan bumi menurun (Simkin dan Fiske dalam Nomanbhoy dan Satake, 1995). bencana tersebut menjadi salah satu bencana terbesar di dunia.

Selain bencana tsunami akibat letusan gunung api, wilayah Indonesia juga sangat rentan terhadap gempa bumi. Salah satu bencana gempa bumi yang baru terjadi, berdampak besar, serta menimbulkan rangkaian bencana selain gempa adalah gempa Palu 2018. Pada 28 September 2018, BMKG mengeluarkan press release yang cukup mengguncang penduduk Indonesia. Terdeteksi gempa dengan Magnitudo 7.7 pada hari itu, pukul 17:02:44 WIB, berlokasi di 0,18 LS dan 119, 85 BT yang berjarak sekitar $26 \mathrm{~km}$ dari Kabupaten Donggala, Provinsi Sulawesi Tengah (Badan Meteorologi Klimatologi dan Geofisika, 2018a). Berdasarkan hasil permodelan yang dilakukan oleh BMKG, tsunami dengan ketinggian maksimum 3 meter berisiko terjadi di daerah Palu sekitar 10 menit setelah gempa (Badan Meteorologi Klimatologi dan Geofisika, 2018a). Pada hari yang sama, BMKG mengeluarkan sebuah ulasan yang membahas dan meralat informasi gempa tersebut. Gempa tersebut ternyata memiliki magnitudo 7.4 dengan OT 17:02:45 WIB, terjadi pada kedalaman $11 \mathrm{~km}$ (Badan Meteorologi Klimatologi dan Geofisika, 2018b). Bencana tersebut menyebabkan 2.256 korban jiwa, 1.309 laporan orang hilang, lebih dari 4.600 orang luka berat, lebih dari 36.000 orang luka ringan, dan lebih dari 223.000 orang mengungsi.

Fakta di atas menggambarkan urgensi mitigasi bencana yang baik. Diperlukan integrasi dari berbagai bidang keilmuan untuk dapat mengenali resiko-resiko bencana. Pada penelitian ini digunakan metode geofisika, gayaberat, untuk mengetahui sesar-sesar penyebab gempa serta daerah-daerah yang memiliki risiko likuifaksi tinggi. Dengan memanfaatkan data sebaran gravitasi satelit TOPEX penelitian ini bertujuan untuk mendelineasi area yang memiliki nilai rendah pada Complete Bouguer Anomaly Map sebagai respon dari rendahnya litodensitas. Dengan melakukan pengolahan dari data observasi Satelite TOPEX yang berupa FAA (Free Air Anomaly), Complete Bouguer Anomaly Map didapatkan melalui koreksi bouguer dan medan yang telah melalui penyesuaian rentang nilai dari koreksikoreksi tersebut sehingga menghasilkan peta yang representatif. Selanjutnya, dilakukan analisis zonazona dengan densitas rendah untuk menentukan area yang memiliki potensi akan bahaya likuifaksi sebagai dampak lanjutan dari proses tektonik tersebut.

\section{Tektonik Regional dan Potensi Bencana Alam}

Sulawesi, sebuah pulau di bagian timur Kepulauan Indonesia dengan luas area sekitar $172.000 \mathrm{~km}^{2}$ (pulau utama) dan $188.000 \mathrm{~km}^{2}$ dengan kepulauan di sekitarnya (Van Bemmelen, 1949), merupakan area yang sangat kompleks secara tektonik. Kompleksitas tersebut menghasilkan fisiografi yang unik. Van Bemellen membagi fisiografi Sulawesi ke dalam tujuh zona: North Arm, East Arm, Banggai Archipelago, Southeast Arm, Buton Archipelago dan Tukang Besi Island, South Arm, dan Central Besi (Van Bemmelen, 1949). Sulawesi adalah hasil dari konvergensi aktif tiga lempeng atau triple junction yang mempertemukan antara Lempeng Eurasia, Pasifik-Filipina, dan IndiaAustralia (Bellier dkk., 2006; Hall, 2002; Prasetya dkk., 2001; Socquet dkk., 2006). Sukamto dan Hamilton menyatakan dalam (Hall, 2002) bahwa secara tektonik Sulawesi dibagi menjadi beberapa bagian: West Sulawesi magmatic arc, Central Sulawesi Methamorphic Belt, East Sulawesi Ophiolit, dan microcontinental blocks of Banggai-Sula and Button-Tukang Besi. Berdasarkan studi yang dilakukan oleh beberapa peneliti, didapati bahwa beberapa mikroblok di area Sulawesi telah mengalami rotasi akibat aktivias lempeng-lempeng yang kompleks tersebut (Hall, 2002; Socquet dkk., 2006). 


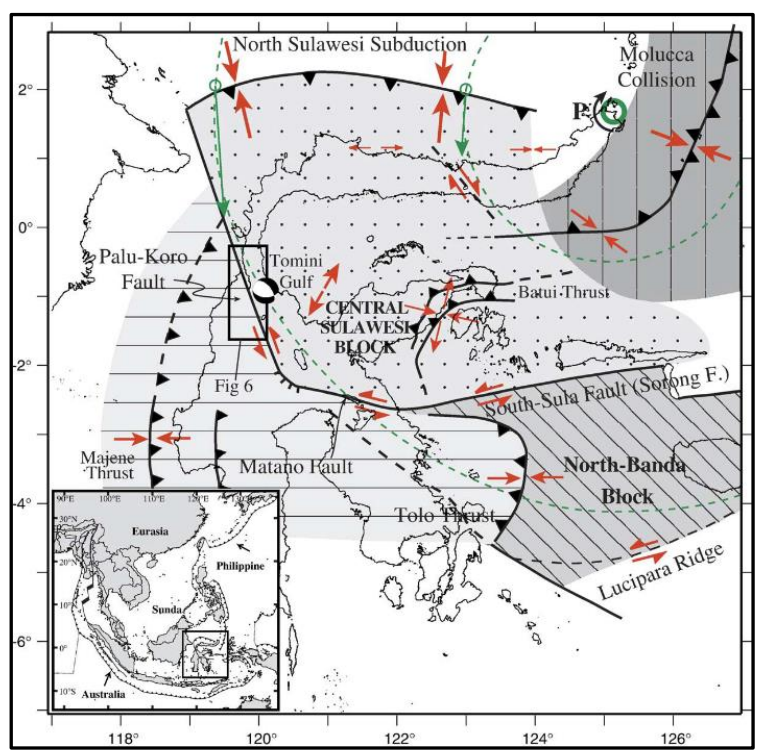

Gambar 1. Tektonik regional Sulawesi. Terjadi subduksi di utara Sulawesi oleh Lempeng FilipinaPasifik yang menghasilkan North Sulawesi Subduction. Sesar Palu-Koro bercabang menjadi dua, vaitu Sesar Matano dan Sesar Lawanopo.

Menurut beberapa peneliti (co: Audley-Charles dkk., 1972; Katili, 1978; Bergman dll) dalam (Hall, 2002) pada Oligosen Akhir-Miosen Awal terdapat tumbukan antara Blok Sulawesi Barat dan Blok Sulawesi Timur. Hal ini dibuktikan dengan ditemukannya ofiolit dan batuan metamorf ofiolitik yang mengindikasikan umur yang sama (Hall, 2002). Pada Miosen Awal, mikrokontinen dari Australia bertumbukan dengan Sulawesi di bagian tenggara. Pada Miosen Akhir berkembanglah fase ekstensional yang membentuk beberapa cekungan di area Banda menurut Hall dan Wilson, 2000; Hall, 2002 dalam (Bellier dkk., 2006). Pada Awal Pliosen terjadi kolisi tahap akhir antara Sulawesi East Arm dengan blok Baggai-Sula yang menyebabkan berkembangnya struktur-struktur seperti lipatan, sesar naik, serta uplift di daerah Sulawesi bagian tengah dan barat ( Hall dan Wilson, 2000; Hall, 2002; Van Leeuwen dan Muhardjo, 2005; Bergmen dkk., 1996; Polve dkk., 2001 dalam Bellier dkk., 2006). Fase ini juga diperkirakan menjadi tahap awal pembentukan Sesar Palu-Koro (Polve dkk., 2001 dalam (Bellier dkk., 2006).

Sesar Palu-Koro merupakan salah satu sesar terbesar di Sulawesi dengan pergerakan sekitar 42 $\mathrm{mm} /$ tahun (Socquet dkk., 2006). Sesar ini menerus dari arah barat laut - tenggara dari Palu hingga Poso dan bercabang menjadi Sesar Matano dan Sesar Lawanopo (Socquet dkk., 2006). Secara geomorfologi, kemenerusan Sesar Palu-Koro dimanifestasikan oleh adanya Cekungan Palu yang dibatasi oleh pegunungan dengan arah relatif barat laut-tenggara (mendekati utara-selatan) yang membentuk wine glass valley dan triangular facet pada dasar pegunungan (Tjia dan Zakaria, 1974; Beaudouin, 1998 dalam Bellier dkk., 2006)). Hal ini membuat daerah Sulawesi Tengah, terutama di area Sesar Palu-Koro memiliki resiko tinggi terhadap gempa dan bencana-bencana alam lain yang berhubungan dengan gempa seperti tsunami dan likuifaksi. Setidaknya 19 gempa bumi yang bersifat merusak telah terjadi dalam kurun waktu 1910 hingga 2013 (Supartoyo dkk., 2014). Enam gempa berpotensi tsunami pernah terjadi di Selat Makassar dan beberapa di antaranya berhubungan dengan Selat Palu-Koro (Socquet dkk., 2019). Palu adalah salah satu kota yang memiliki resiko kegempaan yang tinggi. Terdapat delapan kecamatan di Kota Palu: Palu Barat, Palu Timur, Palu Selatan, Palu Utara, Tatanga, Mantikulore, dan Taweli dan Ulujadi, di mana semua kecamatan berresiko tinggi gempa dan hanya Kecamatan Ulujadi yang berisiko sedang (Rusydi dkk., 2018).

\section{LANDASAN TEORI \\ Metode Gravitasi}

Metode Gravitasi adalah salah satu metode geofisika yang mengukur variasi medan gravitasi bumi akibat perbedaan nilai densitas dari material dibawah permukaan (Reynolds, 2011). Tujuan dari penelitian ini yaitu untuk mengetahui distribusi rapat massa. Tujuan utama dari penelitian menggunakan metode gaya berat ini yaitu untuk memberikan gambaran lapisan bawah permukaan melalui pendekatan fisis (Telford dkk., 1990).

Teori yang mendasari Metode Gravitasi adalah Hukum gravitasi yang dikemukakan oleh Sir Isaac Newton (1642-1727), yang menyatakan bahwa gaya tarik-menarik antara dua partikel sebanding dengan perkalian kedua massanya dan berbanding terbalik dengan kuadrat jarak antara pusat keduanya, jadi semakin jauh jarak kedua benda tersebut maka gaya gravitasi semakin kecil dan sebaliknya. Hukum gravitasi Newton menyatakan bahwa gaya antara dua buah partikel bermassa $m_{1}$ dan $m_{2}$ berbanding langsung dengan hasil kali kedua massa tersebut dibagi dengan kuadrat jaraknya, seperti pada persamaan berikut:

$$
F=G \frac{m_{1} m_{2}}{r^{2}} \hat{\mathrm{r}}
$$


keterangan:

$$
\begin{aligned}
& E(r)=-G \frac{m_{1}}{r^{2}} \hat{\mathrm{r}} \\
& F=m g \\
& g=\frac{F}{m_{2}}=\frac{\frac{-G m_{1} m_{2}}{R^{2}}}{m_{2}} \\
& g=-G \frac{m_{1}}{R^{2}} \\
& g=-G \frac{\rho V}{R^{2}}
\end{aligned}
$$

$$
\begin{array}{ll}
\mathrm{F} & \text { : gaya }(\mathrm{N}) \\
\mathrm{G} & : \text { konstanta Gravitasi universal }=6.673 \times 10^{-11} \\
\mathrm{Nm} & 2 / \mathrm{kg}^{2} \\
\mathrm{M} & : \text { massa benda } \mathrm{M}(\mathrm{kg}) \\
\mathrm{m} & : \text { massa benda } \mathrm{m}(\mathrm{kg}) \\
\mathrm{R} & : \text { jarak antar pusat massa benda }(\mathrm{m}) \\
\mathrm{g} & : \text { percepatan }\left(\mathrm{m} / \mathrm{s}^{2}\right) \\
\mathrm{V} & \text { : Volume }\left(\mathrm{m}^{3}\right) \\
\mathrm{P} & \text { : Densitas Batuan }(\mathrm{g} / \mathrm{cc})
\end{array}
$$

Dari persamaan diatas diketahui bahwa nilai percepatan gravitasi sebanding dengan nilai densitas benda.

\section{Filter Tilt Derivative}

Filter tilt derivative digunakan untuk mempertegas batas anomali gravitasi dimana pada kasus ini sangat berguna untuk melakukan identifikasi struktur-struktur yang berkembang di daerah penelitian. Filter ini membatasi frekuensi anomali residual yang masuk dengan menerapkan fungsi tangensial. Dengan kata lain, filter ini memasukan dua keseimbangan efek pemfilteran yaitu vertical derivative dan total horizontal derivative. Whitehead \& Musselman (2007), menganjurkan penggunaan filter Tilt-Derivatives untuk pemetaan struktur (Gambar 2).

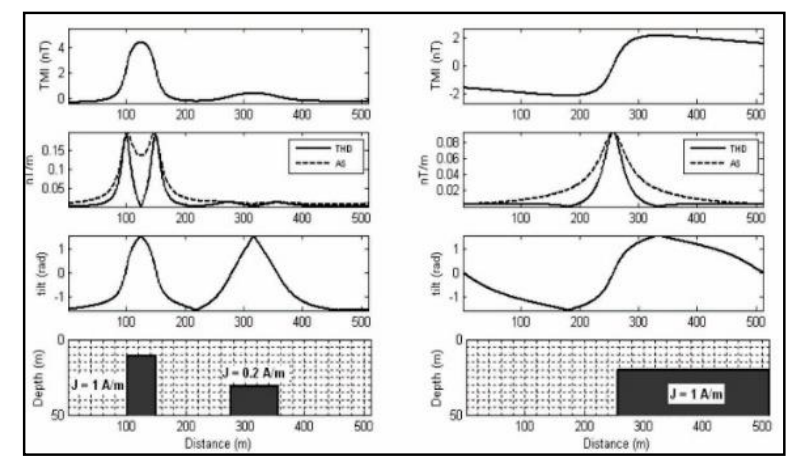

Gambar 2. Penerapan filter derivatif pada anomali TMI (Arisoy dan Dikmen, 2013).

\section{Data Satelite Gravity}

Konsep dasar dari satelit gravimetri yaitu mendeteksi perubahan medan gravitasi bumi dengan cara memonitor perubahan jarak yang terjadi antara pasangan dua satelit gravimetri pada orbitnya. Kedua satelit ini saling melaju pada track orbit dengan jarak satelit satu ke satelit kedua sekitar 220 kilometer. Satelit gravimetri mempunyai akurasi $1 \mathrm{~cm}$ untuk tinggi geoid, dan $1 \mathrm{mGal}$ untuk gravity anomali, pada spasial grid 100 kilometer dipermukaan bumi bahkan kurang (Chelton et al, 2001). Pada penelitian ini penulis menggunakan data dari satelit TOPEX/Poseidon.

Pada data satelite gravity yang didapatkan berupa FAA (Free Air Anomaly) yang mana data tersebut tidak membutuhkan Free Air Correction (FAC) karena pengukuran berada pada datum elevasi yang sama. Koreksi lintang juga tidak dibutuhkan dalam pengolahan karena alat telah mengkalkulasi pengaruh nilai gravitasi terhadap perbedaan lintang. Selain itu, dengan jarak dari pusat massa bumi terhadap lintasan orbit satelit perbedaan percepatan gravitasi yang di timbulkan oleh perbedaan sudut lintang tidak terlalu berpengaruh. Koreksi-koreksi konvensional pada gravitymeter Lacosta Romberg pada pengukuran ground gravity seperti tinggi alat, koreksi drift atau kemuluran pegas juga tidak dipelukan. Koreksi yang diperlukan pada data satelite gravity hanya koreksi bouguer dan medan untuk mengkompensasi kelebihan atau kekurangan massa terhadap nilai pembacaan pada satelite TOPEX.

\section{Koreksi Bouguer}

Koreksi Bouguer diperhitungkan karena ada efek tarikan dari massa batuan yang berada di stasiun dan bidang datum dengan asumsi memiliki jari-jari tak terhingga dengan tebal $h$ (meter) dan densitas $\rho$ (gr/cc) (Gambar 3). Nilai koreksi Bouguer dapat dicari dengan persamaan

$$
B C=2 \pi g \rho h
$$

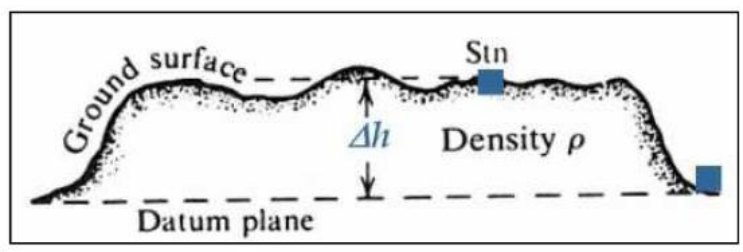

Gambar 3. Ilustrasi koreksi Bouguer.

\section{Koreksi Medan}

Koreksi medan dilakukan karena pada titik pengukuran terdapat efek topografi dan perbedaan elevasi yang besar, seperti bukit dan lembah di sekitar stasiun pengukuran, sehingga dilakukan koreksi pada anomali bouguer sederhana, dimana topografi tersebut mempengaruhi pembacaan karena gravitasi yang bersifat konservatif dan 
mengurangi nilai pembacaan dari pada keadaan ideal (Gambar 4).

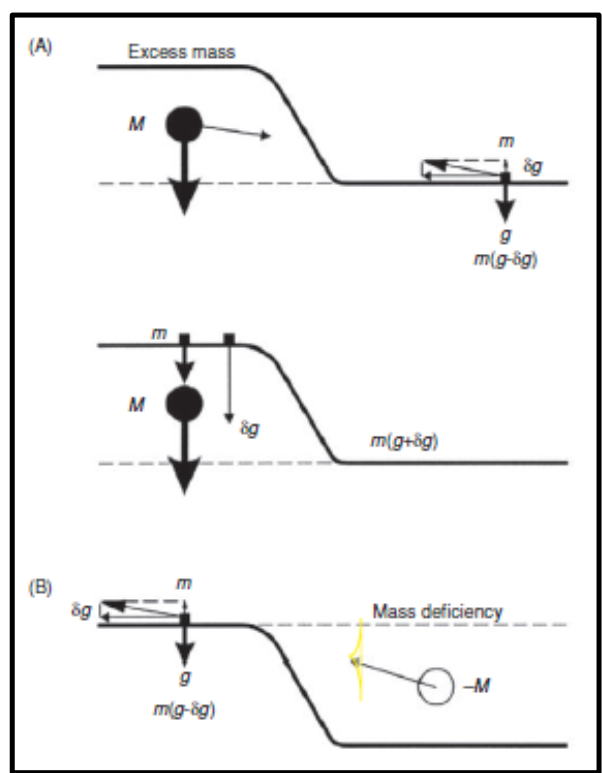

Gambar 4. Koreksi medan.bouguer dan medan diperkecil agar data obervasi gravitasi berupa FAA dapat dihilangkan nilai gravitasi akibat variasi kelebihan dan kekurangan massa batuan pengaruh topografi tanpa menghilangkan informasi variasi gravitasi akibat perbedan nilai lito-densitas.

\section{METODOLOGI}

\section{Daerah Penelitian}

Penelitian ini menggunakan metode gravitasi akibat gravitasi bumi yang disebabkan karena variasi lito-densitas. Menggunakan data observasi gravitasi satelite dari satelite TOPEX. Dengan luas area penelitian sebesar $175.629 \mathrm{~m} \times 215.199 \mathrm{~m}$ atau $37.274 \mathrm{~km}^{2}$. Penelitian dilakukan di daerah Sulawesi Tengah dengan tujuan mendeleniasi struktur sesar besar Palu Koro serta melakukan zonasi sebagai referensi area rawan bencana berdasarkan litodensitas yang dicerminkan oleh variasi nilai gravitasi pada daerah tersebut (Gambar 5).

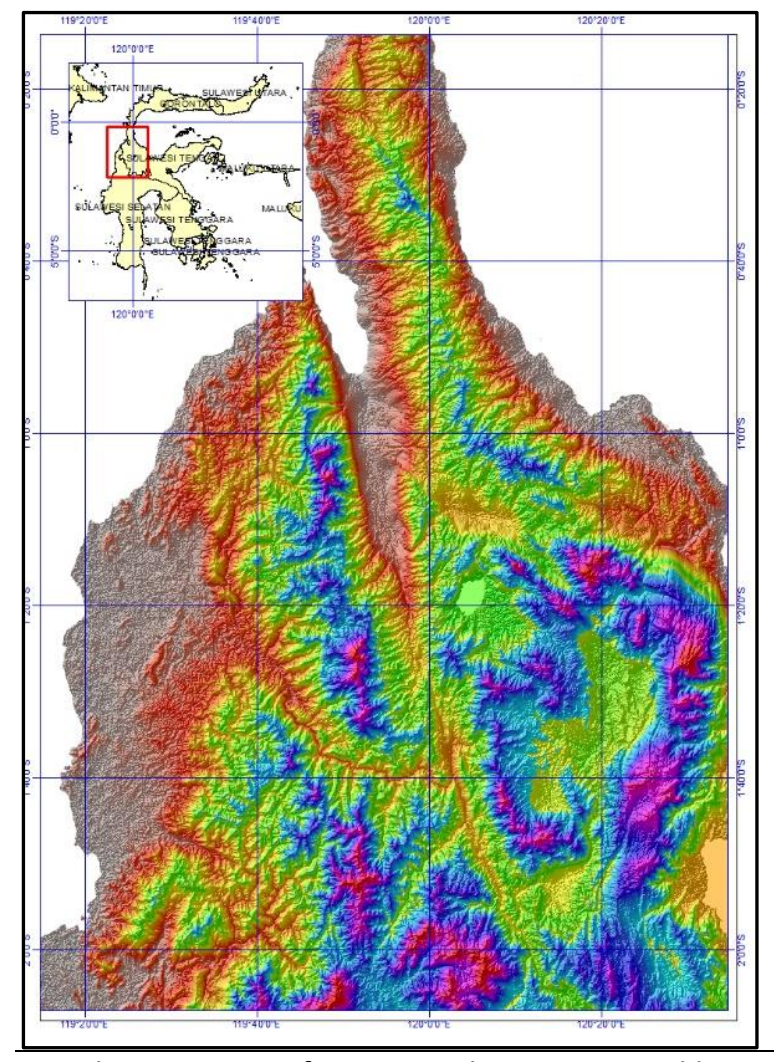

Gambar 5. Topografi area penelitian. Peta ini dibuat berdasarkan data SRTM. Area berwarna ungu merupakan area dengan elevasi tinggi sedangkan area dengan warna abu-abu merupakan area dengan elevasi rendah.

\section{Diagram Alir Pengolahan}

Data yang didapatkan berupa FAA (Free Air Anomaly). Yang kemudian akan dilakukan koreksi bouguer serta medan untuk mendapatkan Complete Bouguer Anomaly. Terdapat empat perlakuan pada koreksi bouguer dan medan untuk mendapatkan CBA yang merepresentasikan kondisi geologi sebenarnya.

Permasalahan yang muncul ketika melakukan pengolahan data gravitasi secara konvensional dengan persamaan koreksi bouguer dan medan yang telah ditemukan adalah: data CBA yang telah didapat tidak menggambarkan keadaan lito-densitas dan menjadi data rusak karena fungsi topografi pada koreksi bouguer tersebut terlalu dominan sehingga hasil reduksi malah menampakan bentukan topografi yang terbalik. Hal tersebut terjadi karena operasi pengurangan atau reduksi nilai gravitasi pada koreksi bouguer. Daerah penelitian memiliki rentang nilai elevasi sebesar 4923 meter, dengan elevasi maksimal 2397 meter dan elevasi minimal -2526 meter. Hal tersebut yang menyebabkan nilai koreksi bouguer juga memiliki rentang yang cukup besar 
dengan nilai maksimal $241.21 \mathrm{mGal}$ dan nilai minimal $254.19 \mathrm{mGal}$. Data FAA yang didapat memiliki rentang yang lebih kecil, yaitu $249.7 \mathrm{mGal}$ hingga$74.3 \mathrm{mGal}$, sehingga apabila dilakukan reduksi dari nilai koreksi bouguer pada data observasi gravitasi tersebut malah menunjukan ekspresi topografi yang terbalik karena nilai koreksi bouguer dan medan yang terlalu besar akan mengurangkan nilai observasi menjadi sangat kecil. Untuk itu, rentang dari koreksi dari data TOPEX yang telah didapat dilakukan empat perlakuan pengolahan data gravitasi berupa koreksi bouguer dan koreksi medan. Keempat perlakukan yang diberikan pada data observasi satelite tersebut diantaranya adalah:

1. Memperkecil rentang pada koreksi bouguer dan medan.

2. Memperkecil rentang pada koreksi bouguer

3. Memperkecil rentang pada koreksi medan

4. Tidak memperkecil rentang pada kedua koreksi.

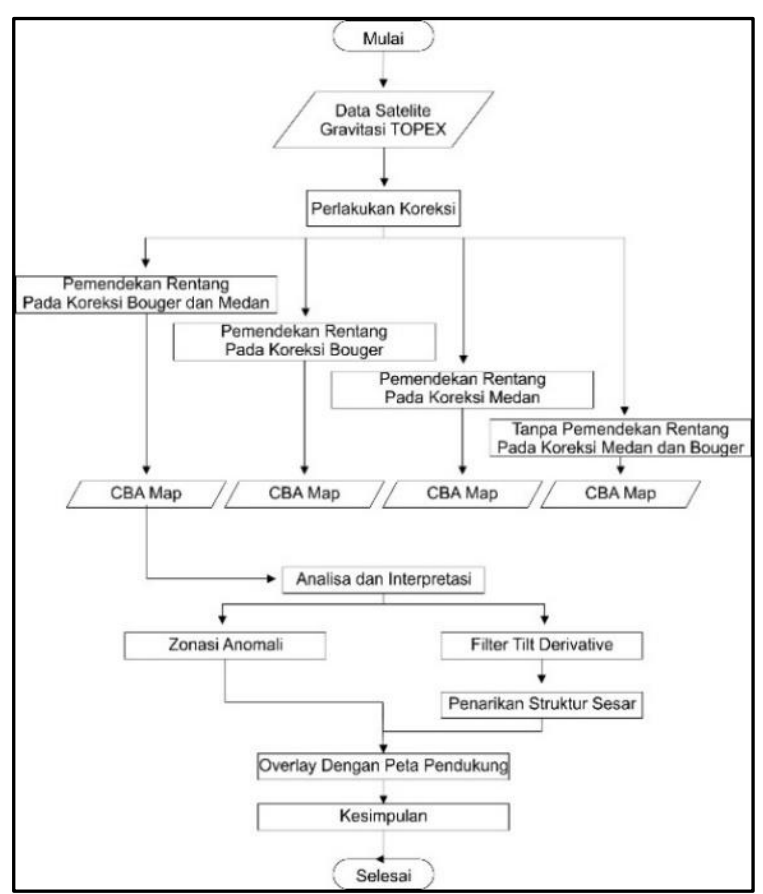

Gambar 6 Diagram Alir Penelitian

Dari keempat perlakuan tersebut dibuat peta yang nantinya akan dibandingkan untuk mengetahui perlakukan mana yang menghasilkan data yang mencerminkan keadaan geologi sebenarnya, yang telah menghilangkan efek variasi kelebihan dan kekurangan massa serta menghilangkan efek topografi.

Pada penelitian ini kami menekankan pada pengolahan gravitasi unconventional yaitu dengan cara memperkecil rentang nilai dari koreksi bouguer yang terlalu signifikan akibat variasi elevasi yang juga terlalu signifikan. Koreksi bouguer konvensional adalah koreksi yang dilakukan tanpa menggunakan pemendekan rentang nilai atau mengubah konstanta pengali, sedangakan pada koreksi Bouguer unconventional dilakukan pemendekan rentang nilai atau memperkecil kostanta pengali. Pemendekan rentang nilai tersebut dilakukan dengan cara membagi koreksi bouguer konvensional dengan konstanta yang sesuai. Berdasarkan rumus konvensional konstanta koreksi bouguer adalah

$$
\text { 0.04193. } \rho . h
$$

Ternyata, pada kasus pengolahan gravitasi TOPEX daerah ini konstanta tersebut tidak menghasilkan gambaran yang sesuai apabila kontras elevasi terlalu tinggi. Oleh karena itu, pada pengolahan ini digunakan konstanta baru, yaitu 0.004193 . Konstanta baru tersebut adalah hasil dari koreksi bouguer konvensional dibagi 10 . Hal tersebut juga dilakukan pada koreksi medan.

Setelah dihasilkan peta yang cukup representatif, peta hasil pengolahan data gravitasi satelit tersebut diinterpretasi dan dianalisis. Interpretasi tersebut menghasilkan peta zonasi anomali. Analisa matematis juga dilakukan dengan menerapkan filter tilt derivative untuk mempertegas kemenerusan struktur sesar berdasarkan data gravitasi.

Selanjutnya, dari hasil analisa dan interpretasi dilakukan proses Map Overlay dengan citra satelit dan peta geologi untuk menguji kesesuaian hasil pemrosesan data gravitasi dengan keadaan geologi yang sebeneranya. Tahap terakhir adalah pembuatan kesimpulan dari hasil pengolahan, analisa, dan interpretasi yang telah dilakukan.

\section{HASIL DAN PEMBAHASAN TOPEX Gravity Map}

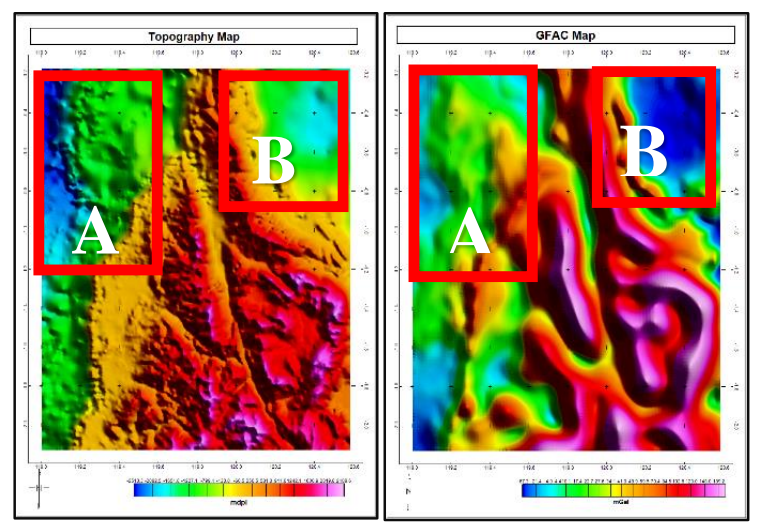

Gambar 7. TOPEX Gravity Map 
Peta diatas merupakan peta FAA (Free Air Anomaly) dari satelit TOPEX. Peta tersebut masih memiliki efek topografi pada nilai pembacaannya, yang disebabkan oleh variasi kelebihan dan kekurangan massa. Medan daerah penelitian juga masih memberikan efek yang terlalu kuat sehingga peta yang dihasilkan kurang menggambarkan litodensitas yang sebenarnya. Pengaruh topografi masih sangat kuat, terlihat dari bentuk data gravitasi TOPEX yang menunjukan kemiripan dengan pola ekspresi topografi. Hal ini ditunjukkan dengan daerah laut yang berwarna hijau hingga biru pada peta topografi memiliki nilai gravitasi yang rendah pada peta GFAC dibanding daerah daratan yang digambarkan dengan warna orange hingga merah pada peta topografi memiliki nilai gravitasi yang relative tinggi pada peta GFAC. Area $A$ memiliki elevasi yang lebih rendah dibandingkan area $B$ namun pada hasil pengukuran TOPEX area A memiliki nilai gravitasi yang lebih tinggi dibanding area $B$. Kemungkinanya pada area $A$ setelah dilakukan koreksi akan memiliki nilai gravitasi yang relatif tinggi.

\section{Perbandingan Hasil Pengolahan}

Dari hasil pengolahan yang telah dilakukan, Peta A menunjukkan nilai gravitasi yang tidak terpengaruh efek topografi dan tetap menampakan informasi lito-densitas. Sedangkan pada perlakukan yang lain pengolahan yang dilakukan bukan hanya telah menghilangkan efek topografi tetapi justru juga menghilangkan infomasi dari lito-densitas atau dapat disebut dengan istilah overcorrected. Hal tersebut menyebabkan peta yang dihasilkan tidak representatif dan tidak dapat dianalisis. Peta B, C, dan $D$ justru menampakan bentukan ekspresi topografi terbalik dikarenakan koreksi yang berlebihan.

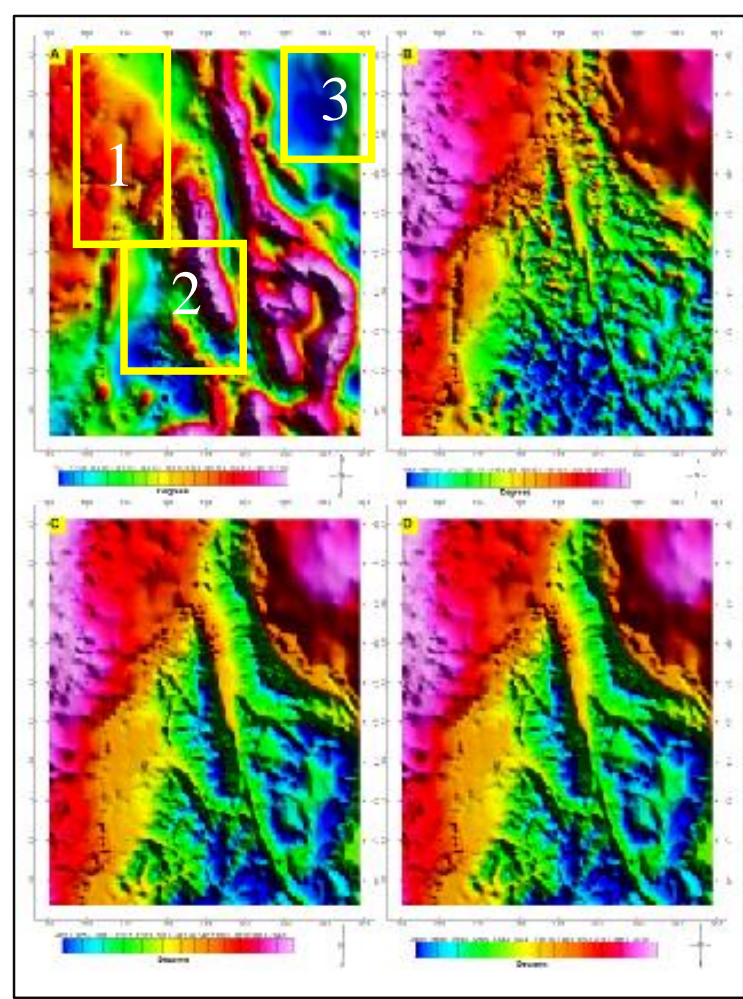

Gambar 8 Perbandingan Hasil Perlakukan Pengolahan Gambar A merupakan hasil dari perlakukan pertama yaitu memperpendek rentang nilai koreksi bouguer dan koreksi medan. Gambar B merupakan hasil dari perlakukan kedua yaitu memperpendek rentang pada koreksi terain.

Tabel 1 Perlakuan pengolahan data gravitasi.

\begin{tabular}{ccc}
\hline & $\begin{array}{c}\text { Pengecilan Rentang } \\
\text { Koreksi Bouguer }\end{array}$ & $\begin{array}{c}\text { Pengecilan Rentang Koreksi } \\
\text { Medan }\end{array}$ \\
\hline A & $\mathrm{v}$ & $\mathrm{v}$ \\
$\mathrm{B}$ & & $\mathrm{v}$ \\
$\mathrm{C}$ & $\mathrm{v}$ & \\
$\mathrm{D}$ & & \\
\hline
\end{tabular}

Bukti bahwa gambar A telah mengandung informasi lito-densitas sebenarnya terdapat pada area yang diberi kotak kuning dengan label nomor 1. Area tersebut memiliki nilai gravitasi yang lebih tinggi dibandingkan pada area yang diberi label nomor 2, di mana area tersebut adalah daratan. Serta pada area label nomor 2 memiliki nilai relatif setara dengan area label nomor 3 di mana area tersebut adalah laut. Selanjutnya, dilakukan interpretasi Peta A untuk menghasilkan zonasi anomali dan penarikan sesar.

\section{Analisa dan Interpretasi CBA Map}

Anomali tinggi pada CBA Map ditunjukan dengan warna orange hingga merah muda yang memiliki rentang nilai $56 \mathrm{mGal}$ hingga $161 \mathrm{mGal}$. Anomali rendah ditunjukan dengan warna hijau 
hingga biru yang memiliki rentang nilai $-14.8 \mathrm{mGal}$ hingga $50 \mathrm{mGal}$. Berdasarkan informasi geologi regional daerah tersebut memiliki variasi batuan yang kompleks.

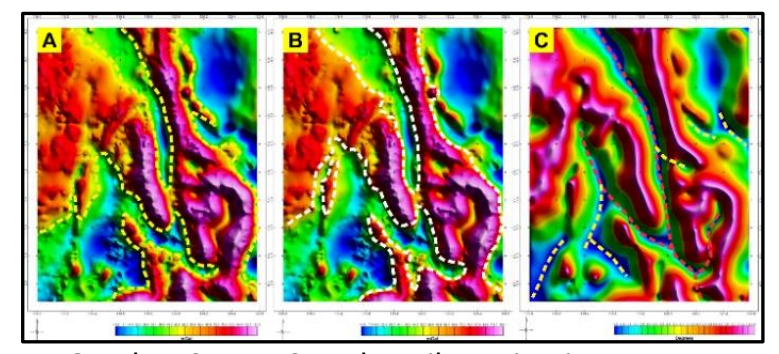

Gambar 9 Peta CBA dan Tilt Derivative. Peta A merupakan peta $\mathrm{CBA}$ yang dilakukan zonasi high anomali. Peta B merupakan peta CBA.

Terdapat batuan sedimen dan juga kristalin baik beku dan juga metamorf. Berdasarkan nilai variasi gravitasi yang menggambarkan lito-densitas area anomali tinggi di interpretasikan sebagai batuan kristalin namun tidak dapat dibedaan antara beku dan metamorf dikarenakan kedua batuan tersebut memiliki densitas yang hampir sama. Area anomali rendah dapat di interpretasikan menjadi dua hal: apabila geometri anomali memiliki pola memanjang dan kelurusan dapat di perkirakan sebagai struktur sesar. Kemudian apabila geometri anomali memilii pola yang luas atau menyebar membentuk area maka dapat diperkirakan sebagai batuan sedimen atau lapukan batuan dari provenance (Batuan Asal).

Selanjutnya untuk melakukan penentukan kelurusan sesar digunakan juga analisa matematis berupa Tilt Derivative untuk memperlihatkan pola kelurusan anomaly yang akan di interpretasikan sebagai sesar. Pada hasil Picking Sesar pada Tilt Derivative Didapatkan beberapa sesar mayor dan sesar minor. Sesar mayor ditunjukan dengan garis merah putus-putus sedangkan sesar minor ditunjukan dengan garis kuning putus-putus. Picking dilakukan pada peta Tilt Derivative yang memiliki nilai sudut rendah yang digambarkan dengan warna biru.

\section{Overlay Hasil Interpretasi}

Dari hasil analisa dan interpretasi didapatkan area high gravity dan low gravity serta kelurusan sesar. Selanjutnya hasil tersebut diproyeksikan pada citra Google Earth untuk mendapatkan gambaran pada daerah penelitian. Terlihat pada Gambar A bahwa kelurusan sesar yang telah dipick pada analisa tilt derivative berada pada lembah. Pada Gambar C dan D dapat diamati bahwa low anomaly juga cenderung berada pada lembah dan elevasi rendah sedangkan high anomaly berada pada punggungan dan pada area laut bagian barat laut.

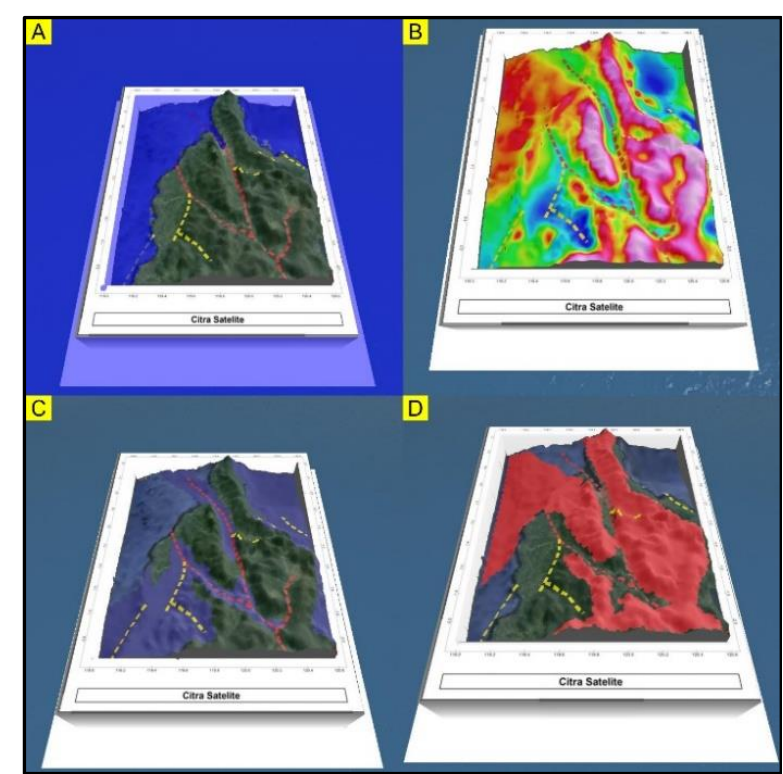

Gambar 10 Overlay Hasil Interpretasi terhadap citra Google Earth. Gambar A menunjukan hasil picking sesar yang dioverlay pada citra Google Earth. Daerah penelitian. Gambar B merupakan CBA Map yang dioverlay pada citra Google Earth. Gambar C adalah hasil low gravity zone yang dioverlay pada citra Google Earth. Gambar D adalah high gravity zone yang dioverlay pda citra Google Earth. Peta-peta tersebut kemudian diaplikasikan ekspresi topografi 3D untuk mempermudah analisa.

Karena sebaran gravitasi mencerminkan sebaran litodensitas maka pada daerah punggungan didominasi oleh batuan yang memiliki densitas serta kekompakan yang lebih tinggi. Punggungan tersebut dapat bertahan dari pelapukan dan erosi berkat resistensi tubuh batuan itu sendiri.

Area high gravity diidentifikasi sebagai area batuan kristalin. Area low gravity yang berada di barat daya peta diinterpretasikan sebagai area batuan sedimen. Kelurusan lembah anomali dengan arah relatif utara-selatan yang berada di tengah peta menunjukkan low gravity. Area tersebut diperkirakan adalah zona sesar utama Palu-koro

\section{Korelasi Terhadap Peta Geologi}

Dilakukan korelasi dengan peta geologi untuk analisa lanjutan. Dari hasil pengolahan unconventional yaitu dengan cara memperkecil konstanta perkalian pada koreksi bouguer serta koreksi medan ternyata cukup menghasilkan 
gambaran lito-densitas yang sesuai dengan keadaan geologi.

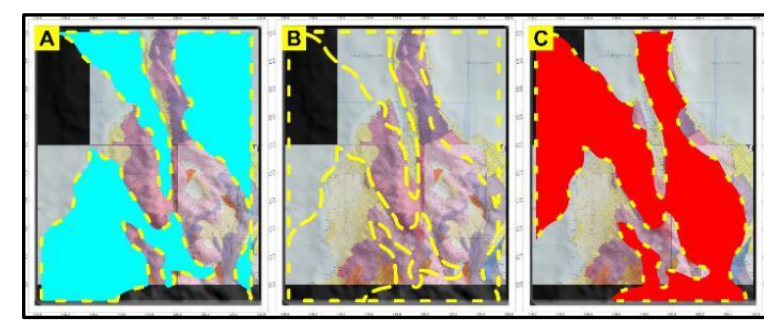

Gambar 11 Overlay Hasil Interpretasi terhadap peta geologi. Peta A merupakan overlay low gravity dengan peta geologi. Peta B merupakan peta geologi daerah penelitian. Peta $\mathrm{C}$ merupakan overlay high graviity dengan peta geologi.

Terbukti bahwa peta geologi area high gravity terletak pada komplek formasi batuan yang didominasi dengan batuan kristalin yang umumnya berada pada daerah punggungan. Serta pada low gravity bertepatan pada area sesar serta batuan sedimen. Terdapat kesesuaian antara data geofisika dengan data geologi. Berdasarkan cara pengolahan baru yang menjadi titik berat pada penelitian ini.

\section{PENUTUP}

\section{Kesimpulan}

Berdasarkan perlakukan pengolahan data secara unconventional yaitu memperkecil kostanta pengali serta analisa peta yang dihasilkan didapatkan kesimpulan sebagai berikut:

- Dalam melakukan koreksi bouguer perlu diperhatian agar besaran pada koreksi bouguer dapat mereduksi efek topografi tanpa menghilangkan informasi litologi. Oleh karena itu dilakukan dengan cara memperkecil rentang koreksi bouguer hingga berada pada rentang data pengukuran.

- Digunakan konstanta pengali pada koreksi bouguer dari $\mathbf{0 . 0 0 4 1 9 3}$ menjadi $\mathbf{0 . 0 0 4 1 9 3}$ untuk menghasilkan peta yang sesuai.

- Hasil pengolahan secara Unconventional terbukti CBA Map yang dihasilkan menggambarkan fenomena geologi sebagai mana mestinya berdasarkan korelasi terhadap peta geologi.

- High gravity diinterpretasikan sebagai batuan kristalin dan low gravity di interpretasikan sebagai sesar dan batuan sedimen. Area ini ditemukan pada daerah pegunungan.

- Pada low gravity yang memiliki pola kelurusan di interpretasi sebagai sesar. Area ini ditemukan di beberapa tempat, salah satunya adalah di area tengah. Kelurusan tersebut diinterpretasikan sebagai zona sesar Palu-Koro. Pada low gravity yang memiliki pola melebar di interpretasikan sebagai batuan sedimen. Area tersebut ditemukan di bagian barat daya dan timur daerah penelitian.

\section{Saran}

Diperlukan pemahaman konsep tentang reduksi nilai gravitasi agar dapat melakukan pengolahan dengan baik dan benar sehingga menghasilkan peta yang sesuai dengan fenomena geologi yang ada. Overlay dengan peta-peta yang sudah dibuat oleh peneliti sebelumnya juga dibutuhkan untuk mengkonfirmasi kebenaran hasil pemrosesan data.

\section{Ucapan Terima Kasih}

Penulis mengucapkan terima kasih kepada Felissa Kaje Lobo yang telah membantu dalam menerjemahkan abstrak tulisan ini.

\section{DAFTAR PUSTAKA}

Arisoy, M.Ö. dan Dikmen, Ü. (2013), "Edge detection of magnetic sources using enhanced total horizontal derivative of the tilt angle", Yerbilimleri/ Earth Sciences, Vol.34, hal. 73-82.

Badan Meteorologi Klimatologi dan Geofisika (2018a), Press Release NO: UM.505/9/D3/IX/2018, Badan Meteorologi Klimatologi dan Geofisika, Jakarta.

Badan Meteorologi Klimatologi dan Geofisika (2018b), Ulasan Guncangan Tanah Akibat Gempabumi Utara Donggala Sulteng 28 September 2018, Badan Meteorologi Klimatologi dan Geofisika, Jakarta. Diambil dari https://www.bmkg.go.id/berita/?p=ulasanguncangan-tanah-akibat-gempabumi-utaradonggala-sulteng-28-september2018\&tag=ulasan-guncangan-tanah\&lang=ID .

Bellier, O., Sébrier, M., Seward, D., Beaudouin, T., Villeneuve, M. dan Putranto, E. (2006), "Fission Track and Fault Kinematics Analyses for New Insight into the Late Cenozoic Tectonic Regime Changes in West-Central Sulawesi (Indonesia)", Tectonophysics, Vol.413, No.3, hal. 201-220. http://doi.org/10.1016/j.tecto.2005.10.036.

Blakely, R.J. (1996), Potential Theory in Gravity and Magnetic Applications, Cambridge University Press, Cambridge.

Cummins, P.R. (2017), "Geohazards in Indonesia: Earth Science for Disaster Risk Reduction - 
Introduction", Geological Society, London, Special Publications, Vol.441, No.1, hal. 1-7. http://doi.org/10.1144/SP441.11.

Hall, R. (2002), "Cenozoic Geological and Plate Tectonic Evolution of SE Asia and the SW Pacific: Computer-Based Reconstructions, Model and Animations", Journal of Asian Earth Sciences, Vol.20, No.4, hal. 353-431. http://doi.org/10.1016/S1367-9120(01)000694.

Harmoko, U., Yulianto, G., Widada, S. dan Herlambang, Y. (2016), Analisis Struktur dan Muka Air Tanah sebagai Klarifikasi Model Konseptual Sistem Panas Bumi Candi Umbul, Kartoharjo, Magelang,

Kearey, P., Brooks, M. dan Hill, I. (2002), An Introduction to Geophysical Exploration, 3 edition., WileyBlackwell, Malden, MA.

Nomanbhoy, N. dan Satake, K. (1995), "Generation Mechanism of Tsunamis from the 1883 Krakatau Eruption", Geophysical Research Letters, Vol.22, No.4, hal. 509-512. http://doi.org/10.1029/94GL03219.

Prasetya, G., de Lange, W. dan Healy, T. (2001), "The Makassar Strait Tsunamigenic Region, Indonesia", Natural Hazards, Vol.24, hal. 295307. http://doi.org/10.1023/A:1012297413280.

Rusydi, M., Efendi, R., Sandra dan Rahmawati (2018), "Earthquake Hazard Analysis Use Vs30 Data In Palu", Journal of Physics: Conference Series, Vol.979, hal. 012054. http://doi.org/10.1088/17426596/979/1/012054.

Santoso, D. (2002), Pengantar Teknik Geofisika, Institut Teknologi Bandung, Bandung.

Socquet, A., Hollingsworth, J., Pathier, E. dan Bouchon, M. (2019), "Evidence of Supershear during the 2018 Magnitude 7.5 Palu Earthquake from Space Geodesy", Nature Geoscience, Vol.12, No.3, hal. 192-199. http://doi.org/10.1038/s41561-0180296-0.

Socquet, A., Simons, W., Vigny, C., McCaffrey, R., Subarya, C., Sarsito, D., Ambrosius, B. dan Spakman, W. (2006), "Microblock Rotations and Fault Coupling in SE Asia Triple Junction (Sulawesi, Indonesia) from GPS and Earthquake Slip Vector Data", Journal of Geophysical Research: Solid Earth, Vol.111, No.B8. http://doi.org/10.1029/2005JB003963.

Supartoyo, S., Sulaiman, C. dan Junaedi, D. (2014), "Kelas Tektonik Sesar Palu Koro, Sulawesi Tengah",
Jurnal Lingkungan dan Bencana Geologi, Vol.5, No.2, hal. 111-128. http://doi.org/10.34126/jlbg.v5i2.68.

Telford, W. (1990), Applied Geophysics, 2 edition., Cambridge University Press, Cambridge.

Telford, W.M., Geldart, L.P. dan Sheriff, R.E. (1990), Google-Books-ID: Q8ogAwAAQBAJ, Applied Geophysics, Cambridge University Press.

Van Bemmelen, R.W. (1949), The Geology of Indonesia: General Geology of Indonesia and Adjacent Archipelagos, Government Printing House, The Hague. 